\title{
Magnetic Properties of MnBi Fine Particles Fabricated Using Hydrogen Plasma Metal Reaction
}

\author{
Keita Isogai*, Masashi Matsuura, Nobuki Tezuka and Satoshi Sugimoto \\ Department of Materials Science, Graduate School of Engineering, Tohoku University, Sendai 980-8579, Japan
}

\begin{abstract}
Fine particles of $\mathrm{MnBi}$ were prepared by the hydrogen plasma metal reaction method and their magnetic properties were investigated. The particle size of the as-prepared MnBi particles was $70-950 \mathrm{~nm}$ with a median diameter of $269 \mathrm{~nm}$. Heat treatment and ball milling with a dispersant improved the magnetic properties of the particles. The sample annealed at $330^{\circ} \mathrm{C}$ for $5 \mathrm{~h}$ in $\mathrm{Ar}$ then ball-milled for $10 \mathrm{~min}$ with a dispersant showed the largest energy product of $105 \mathrm{~kJ} \cdot \mathrm{m}^{-3}$ and a saturation magnetization of $71.0 \mathrm{Am}^{2} \cdot \mathrm{kg}^{-1}$. High coercivity of $1380 \mathrm{kA} \cdot \mathrm{m}^{-1}$ was also obtained for the sample that was ball-milled for $2 \mathrm{~h}$. [doi:10.2320/matertrans.MAW201306]
\end{abstract}

(Received April 24, 2013; Accepted June 24, 2013; Published August 25, 2013)

Keywords: coercivity, magnetization, magnet, remanence, manganese bismuth

\section{Introduction}

Fine particles or nanoparticles of hard magnetic materials are attractive materials for potential use in microactuators, microdevices and nanocomposite magnets. ${ }^{1-4)}$ Several preparation methods have been reported, and they can be classified into three main categories: gas phase methods, ${ }^{5,6}$ ) such as chemical vapor deposition and evaporation; liquid phase methods, ${ }^{7,8)}$ such as liquid-phase reduction and the polyol process; and solid phase methods, ${ }^{9)}$ such as mechanical pulverizing and milling.

Hydrogen plasma reaction methods have been used to produce fine particles of metal alloys and intermetallic compounds. ${ }^{10-15)}$ In this method, the dissociated hydrogen in arc plasmas dissolves in the molten metal and enhances the vaporization of the metal when the hydrogen is emitted. The method has the advantages such simple equipment, low levels of contamination and high productivity. For example, the productivities of $\mathrm{Fe}$ and $\mathrm{Mn}$ are 5.86-7.86 $\times$ $10^{-5} \mathrm{~mol} \cdot \mathrm{s}^{-1}$ and $2.81-6.00 \times 10^{-3} \mathrm{~mol} \cdot \mathrm{s}^{-1}$, respectively. ${ }^{10)}$ Moreover, the composition and size of fine particles can be easily controlled by parameters such as the composition of the mother ingot, $\mathrm{H}_{2}$ concentration and reaction time. ${ }^{16}$ ) Although all types of alloys can be obtained by the hydrogen plasma metal reaction method, the only hard magnetic materials reported have been $\mathrm{Mn}-\mathrm{Al}-\mathrm{C}$ magnets. ${ }^{17)}$ However, because $\mathrm{Mn}-\mathrm{Al}-\mathrm{C}$ magnets must be annealed at temperatures greater than $500^{\circ} \mathrm{C}$ to achieve the transformation from the $\varepsilon$-phase to the $\tau$-phase, grain growth can occur during annealing.

The low temperature phase (LTP) of $\mathrm{MnBi}$ is a ferromagnetic intermetallic phase with a NiAs-type hexagonal crystal structure. Additionally, the LTP of MnBi exhibits a large magnetocrystalline anisotropy $\left(\mathrm{K} \approx 10^{6} \mathrm{~J} \cdot \mathrm{m}^{-3}\right)$ and a positive temperature coefficient of coercivity. ${ }^{18,19)} \mathrm{MnBi}$ is formed by a peritectic reaction between the liquid phase and the Mn phase at temperatures of less than $446^{\circ} \mathrm{C}$. The LTP of $\mathrm{MnBi}$ is transformed from the high temperature phase (HTP) at temperatures of less than $355^{\circ} \mathrm{C} .{ }^{20,21)}$ Because grain growth is suppressed at these low temperatures, the material is suitable for forming hard magnetic ultrafine particles or nanoparticles. However, a long low-temperature annealing process is required to obtain a single LTP with superior magnetic properties. On the other hand, the hydrogen plasma metal reaction method has advantages of direct fabrication of fine particles, low contamination and high productivity. Therefore, in this study we used the hydrogen plasma metal reaction method to prepare fine $\mathrm{MnBi}$ particles.

\section{Experimental Procedure}

Figure 1 shows the experimental procedure. $\mathrm{MnBi}$ ingots with a composition of $\mathrm{Mn}_{100-x} \mathrm{Bi}_{x}(x=50,70)$ were fabricated from metallic $\mathrm{Mn}(99.9$ mass $\%)$ and $\mathrm{Bi}$ (99.9 mass\%) by arc melting under an Ar atmosphere. Particles of $\mathrm{MnBi}$ were prepared using these ingots by the hydrogen plasma metal reaction method. The equipment for the hydrogen plasma metal reaction method consisted of an arc-melting chamber and a metal filter for the collection of particles (Fig. 2). The arc-melting chamber was supplied with $\mathrm{Ar} / \mathrm{H}_{2}(7: 3)$ at a pressure of $0.1 \mathrm{MPa}$. The $\mathrm{Mn}_{x} \mathrm{Bi}_{100-x}$

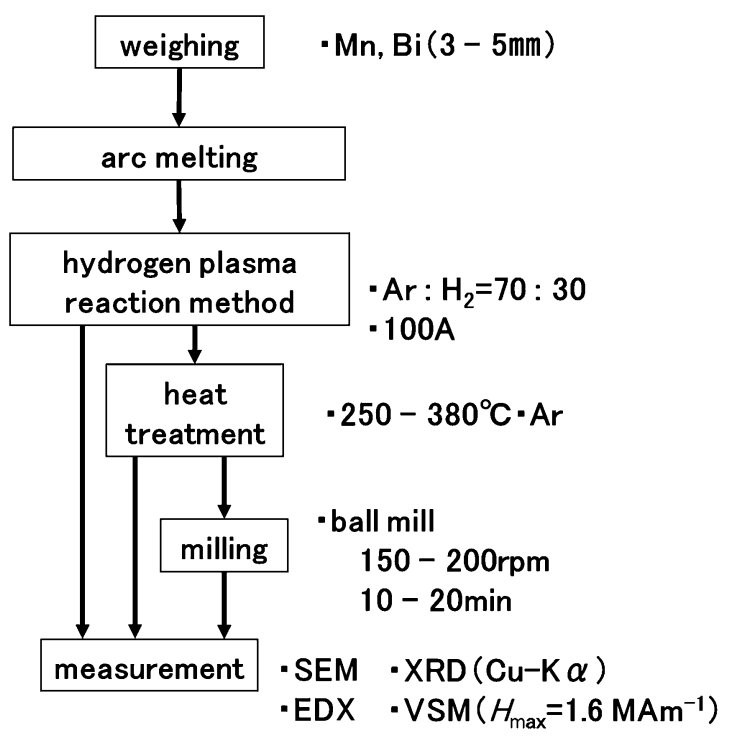

Fig. 1 Flow chart for the experimental procedure. 


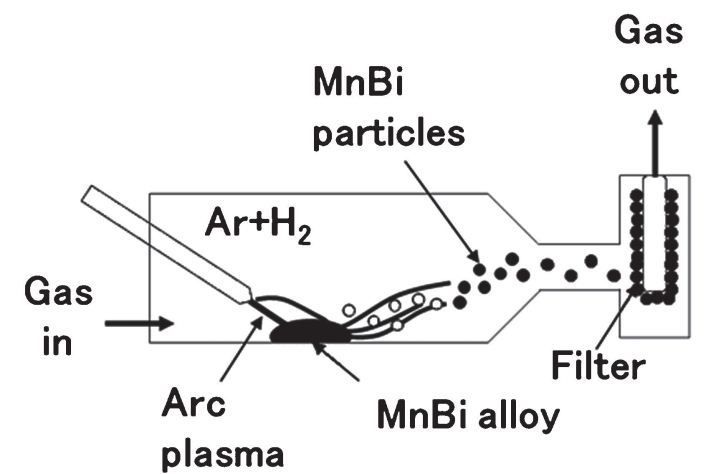

Fig. 2 Equipment for the hydrogen plasma metal reaction.

ingots were melted by the arc plasma and formed fine particles. The arc current for the hydrogen plasma metal reaction was $100 \mathrm{~A}$. The fine particles were carried by the gas flow and collected on the metal filter.

The MnBi particles were annealed at $330^{\circ} \mathrm{C}$ in $\mathrm{Ar}$ to form the LTP and crushed by ball milling at a speed of $150 \mathrm{rpm}$ for 30-120 min to isolate the particles. The solvent for ball milling was heptane, and oleic acid was added as dispersant. After ball milling, the samples were washed with heptane 5 times to remove the dispersant. The washed samples were dried in a glove box to suppress oxidation and the dried powders were used for the measurements.

The magnetic properties were measured by using a vibrating sample magnetometer (VSM) after applying a magnetic pulsed field of $6.4 \mathrm{MA} \cdot \mathrm{m}^{-1}$. The saturation magnetization $\left(\sigma_{\mathrm{s}}\right)$ was evaluated using the magnetization at an applied magnetic field of $1.6 \mathrm{MA} \cdot \mathrm{m}^{-1}$. The energy product $\left((B H)_{\max }\right)$ of the $\mathrm{MnBi}$ particles was calculated by using the theoretical density of the LTP of $\mathrm{MnBi}\left(8.9 \mathrm{Mg} \cdot \mathrm{m}^{-3}\right)$.

The phases present in the particles were characterized by $\mathrm{X}$-ray diffraction (XRD). The size distribution and shape of the particles were observed by scanning electron microscopy (SEM). The chemical compositions of the particles were determined by energy dispersive X-ray spectrometry (EDX).

\section{Results and Discussion}

Initially, we prepared a MnBi ingot with a composition of $\mathrm{Mn}_{50} \mathrm{Bi}_{50}$ by arc melting and the fine particles were fabricated by the hydrogen plasma metal reaction method. However, EDX analysis revealed that the composition of particles was 30.4 at\% Mn-69.6 at\% Bi and the composition was influenced by the evaporation rate of the metals. To fabricate $\mathrm{Mn}_{50} \mathrm{Bi}_{50}$ compositional particles, the composition of the $\mathrm{MnBi}$ ingots used in the hydrogen plasma metal reaction method was altered because of the difference between the nominal composition of the ingot and the EDX composition of the MnBi particles. The $\mathrm{Mn}_{70} \mathrm{Bi}_{30}$ alloy was found to produce $\mathrm{MnBi}$ particles with the desired composition.

Figure 3 shows secondary electron images (SEIs) of the as-prepared $\mathrm{MnBi}$ particles. The particle size distribution of the as-prepared $\mathrm{MnBi}$ particles was also evaluated using 200 particles chosen from the SEI (Fig. 4). The size of the particles was $70-950 \mathrm{~nm}$ with a median diameter $\left(d_{50}\right)$ of $269 \mathrm{~nm}$. EDX analyses also showed that the composition of

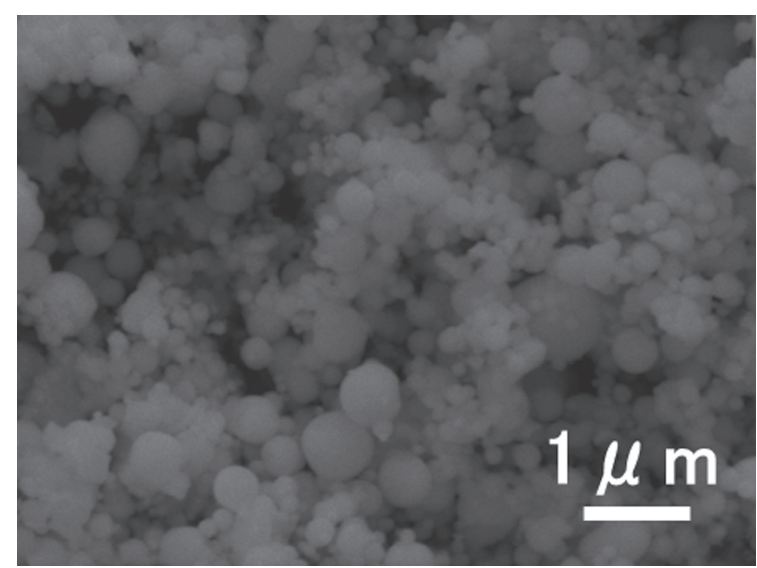

Fig. 3 SEI of the as-prepared MnBi particles.

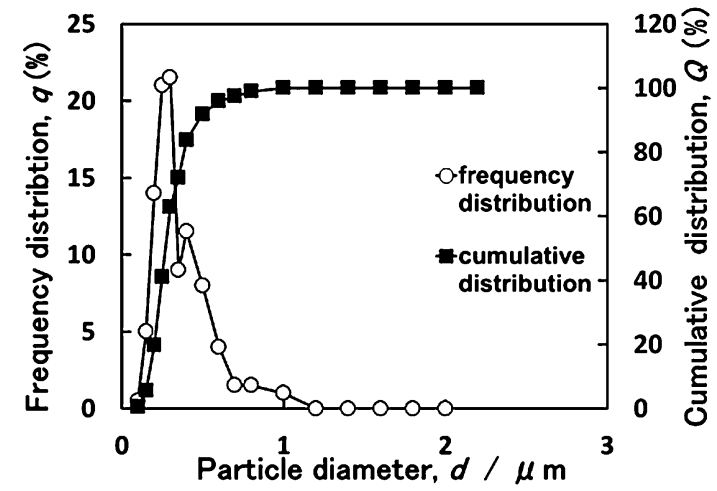

Fig. 4 Particle size distribution of the as-prepared MnBi particles.

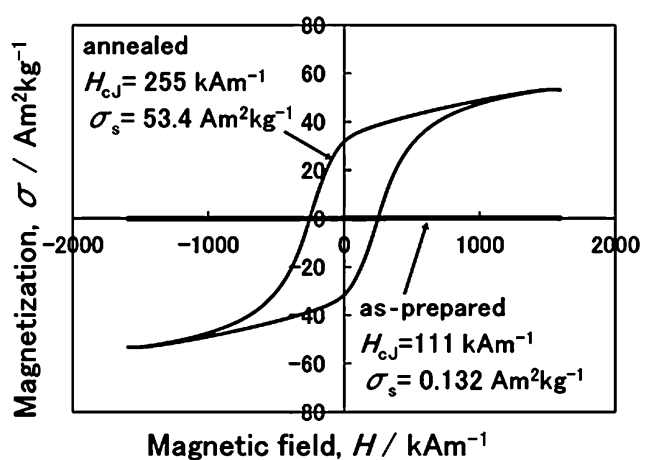

Fig. 5 Hysteresis loops of the as-prepared MnBi particles and the particles annealed at $330^{\circ} \mathrm{C}$ for $5 \mathrm{~h}$ in $\mathrm{Ar}$.

as the prepared MnBi particles was 49.9-50.3 at\% Mn-49.750.1 at $\% \mathrm{Bi}$, which is close to the stoichiometric composition of the MnBi phase.

Figure 5 shows the hysteresis loops of the as-prepared $\mathrm{MnBi}$ particles and the particles heat-treated at $330^{\circ} \mathrm{C}$ for $5 \mathrm{~h}$ in Ar. The magnetization of the as-prepared particles was very low; however, the magnetic properties were dramatically enhanced by annealing. Coercivity $\left(H_{\mathrm{cJ}}\right)$ increased from 111 to $255 \mathrm{kA} \cdot \mathrm{m}^{-1}$, and saturation magnetization $\left(\sigma_{\mathrm{s}}\right)$ increased from 0.132 to $53.4 \mathrm{Am}^{2} \cdot \mathrm{kg}^{-1}$.

Therefore, the phase transformation was caused by annealing and the particles were examined by using XRD. Figure 6 shows the XRD patterns of the as-prepared sample 


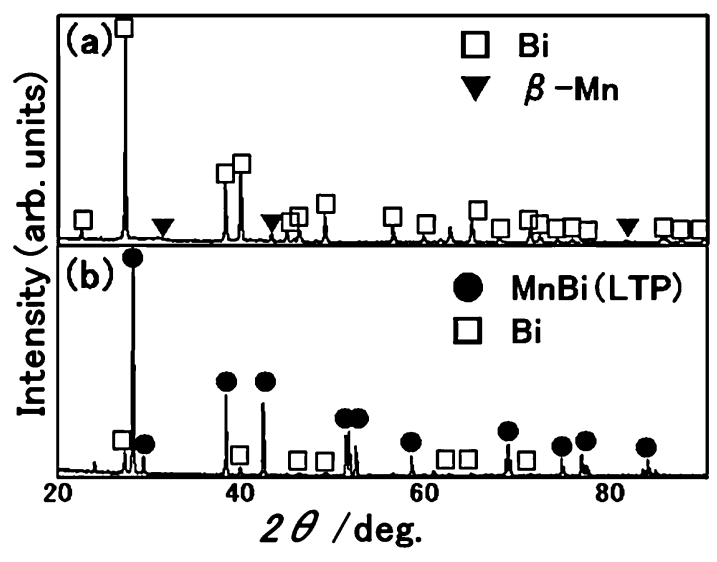

Fig. 6 XRD patterns of (a) the as-prepared MnBi particles and (b) the particles annealed at $330^{\circ} \mathrm{C}$ for $5 \mathrm{~h}$ in Ar.

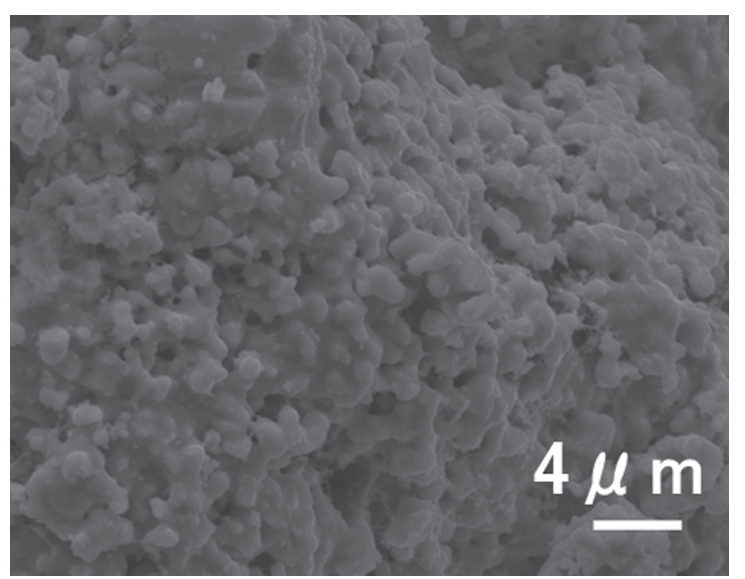

Fig. 7 SEI of the MnBi particles annealed at $330^{\circ} \mathrm{C}$ for $5 \mathrm{~h}$ in $\mathrm{Ar}$.

and the sample annealed at $330^{\circ} \mathrm{C}$ for $5 \mathrm{~h}$ in Ar. The XRD pattern of the as-prepared sample contained only $\mathrm{Bi}$ and $\beta$ Mn peaks. However, MnBi (LTP) and Bi XRD peaks were observed after annealing. Therefore, the formation of the MnBi LTP improved the magnetic properties.

Although the magnetization was improved by annealing, $H_{\mathrm{cJ}}$ was small for $\mathrm{MnBi}$. The microstructure of the particles was observed by SEM. Figure 7 shows the SEI of the MnBi particles annealed at $330^{\circ} \mathrm{C}$ for $5 \mathrm{~h}$ in Ar. The particles agglomerated and joined together, which probably caused the low $H_{\mathrm{cJ}}$.

The annealed particles were crushed by ball milling in order to increase $H_{\mathrm{cJ}}$. After ball milling, the MnBi particles were aligned by applying a magnetic field of $1600 \mathrm{kA} \cdot \mathrm{m}^{-1}$. Figure 8 shows the hysteresis loops of the particles annealed at $330^{\circ} \mathrm{C}$ for $5 \mathrm{~h}$ in $\mathrm{Ar}$ and ball-milled at $150 \mathrm{rpm}$ for $30 \mathrm{~min}$, measured parallel or perpendicular to the magnetic field. $H_{\mathrm{cJ}}$ was $1040 \mathrm{kA} \cdot \mathrm{m}^{-1}$, which was higher than that of the sample shown in Fig. $5\left(H_{\mathrm{cJ}}=255 \mathrm{kA} \cdot \mathrm{m}^{-1}\right)$. Therefore, $H_{\mathrm{cJ}}$ was increased by ball milling. However, the hysteresis loops measured parallel and perpendicular to the magnetic field were similar. Figure 9 shows the SEI of the ball-milled MnBi particles, and the corresponding particle size distribution is shown in Fig. 10. Many agglomerated particles are visible in Fig. 9 and the particle size distribution shown in Fig. 10 is

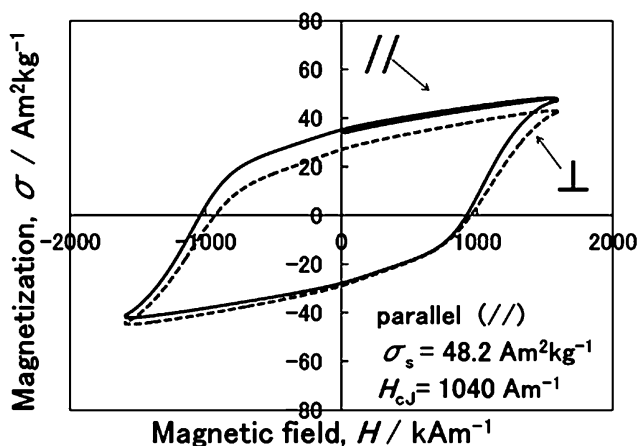

Fig. 8 Hysteresis loops of the aligned $\mathrm{MnBi}$ particles annealed at $330^{\circ} \mathrm{C}$ for $5 \mathrm{~h}$ in $\mathrm{Ar}$ and ball-milled at $150 \mathrm{rpm}$ for $30 \mathrm{~min}$. Measurements were parallel $(/ /)$ or perpendicular $(\perp)$ to the magnetic field.

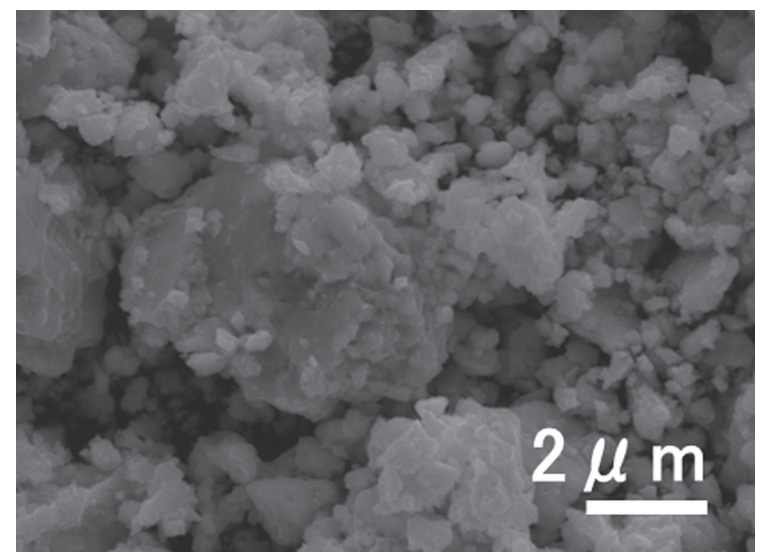

Fig. 9 SEI of the MnBi particles annealed at $330^{\circ} \mathrm{C}$ for $5 \mathrm{~h}$ in $\mathrm{Ar}$ and ballmilled at $150 \mathrm{rpm}$ for $30 \mathrm{~min}$.

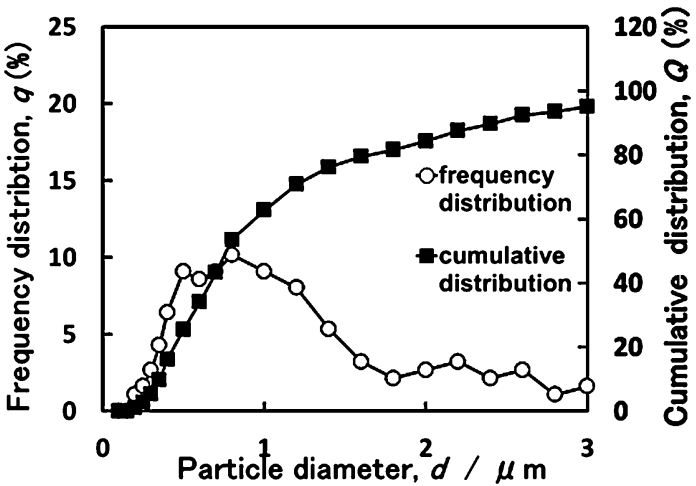

Fig. 10 Particle size distribution of the $\mathrm{MnBi}$ particles annealed at $330^{\circ} \mathrm{C}$ for $5 \mathrm{~h}$ in $\mathrm{Ar}$ and ball-milled at $150 \mathrm{rpm}$ for $30 \mathrm{~min}$.

broad, because the agglomerated particles formed larger single particles, resulting in a large $d_{50}$ of $766 \mathrm{~nm}$. The large agglomerated particles probably prevented the powder from being aligned by the magnetic field.

A dispersant was used during ball milling to inhibit the agglomeration and to improve the alignment of particles. The hysteresis loops of the particles aligned in a magnetic field of $1600 \mathrm{kA} \cdot \mathrm{m}^{-1}$ are shown in Fig. 11. The sample measured parallel to the magnetic field showed a high $H_{\mathrm{cJ}}$ of $1380 \mathrm{kA} \cdot \mathrm{m}^{-1}$, which was higher than that of the sample shown in Fig. $8\left(H_{\mathrm{cJ}}=1040 \mathrm{kA} \cdot \mathrm{m}^{-1}\right)$. In addition, there was 


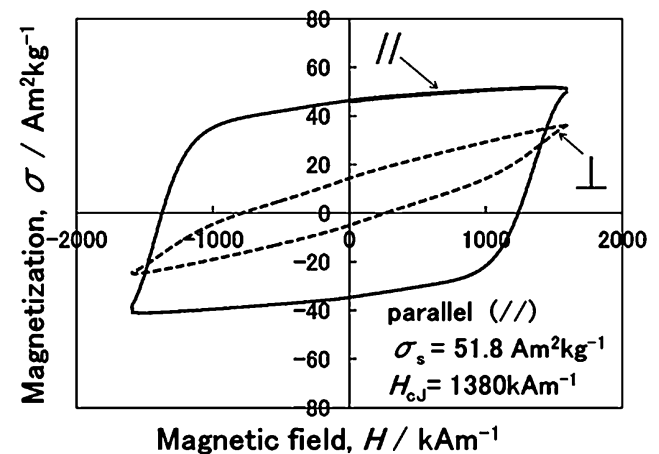

Fig. 11 Hysteresis loops of the aligned $\mathrm{MnBi}$ particles annealed at $330^{\circ} \mathrm{C}$ for $5 \mathrm{~h}$ in $\mathrm{Ar}$ and ball-milled with a dispersant. Measurements were parallel $(/ /)$ or perpendicular $(\perp)$ to the magnetic field.

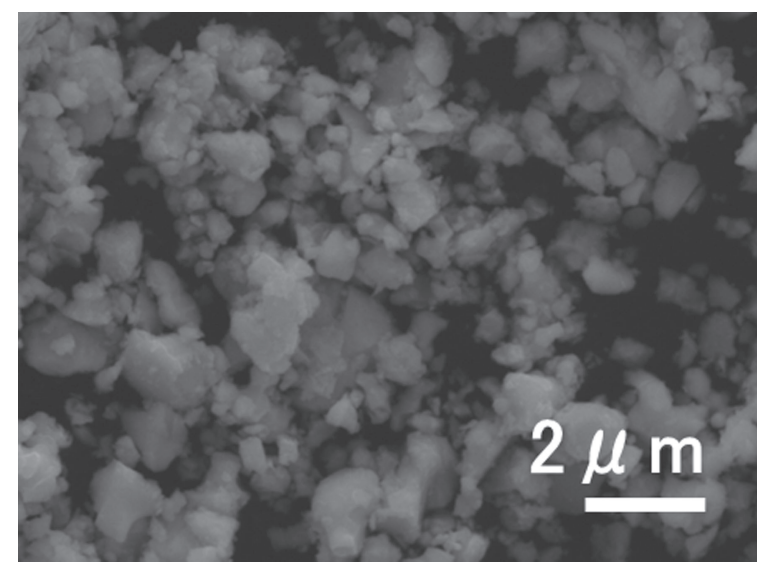

Fig. 12 SEI of the MnBi particles ball-milled with a dispersant.

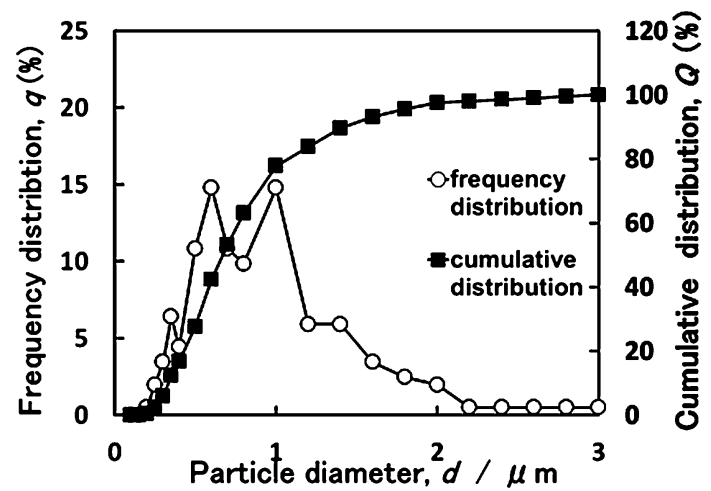

Fig. 13 Particle size distribution of the MnBi particles ball-milled with a dispersant.

a marked difference in the parallel and perpendicular hysteresis loops. Figures 12 and 13 show the SEI and particle size distribution of the $\mathrm{MnBi}$ particles milled with a dispersant. There were many agglomerated particles (Fig. 12) which meant the particle size distribution was broad (Fig. 13). However, the microstructure of the sample milled with dispersant had smaller, more dispersed particles with a $d_{50}$ of $671 \mathrm{~nm}$, compared with the sample milled without dispersant (Figs. 9 and 10). Therefore, the particles could be aligned with a magnetic field and the magnetic properties were improved.
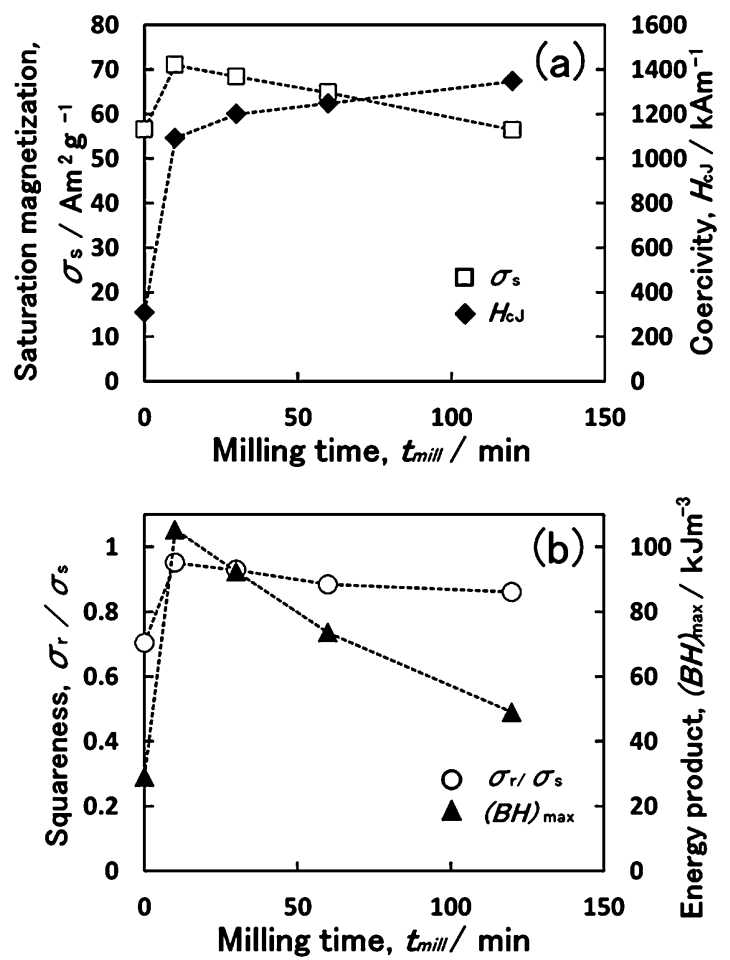

Fig. 14 Dependence of the magnetic properties of $\mathrm{MnBi}$ particles on milling time. (a) $\sigma_{\mathrm{s}}$ and $H_{\mathrm{cJ}}$ and (b) $\sigma_{\mathrm{r}} / \sigma_{\mathrm{s}}$ and $(B H)_{\max }$.

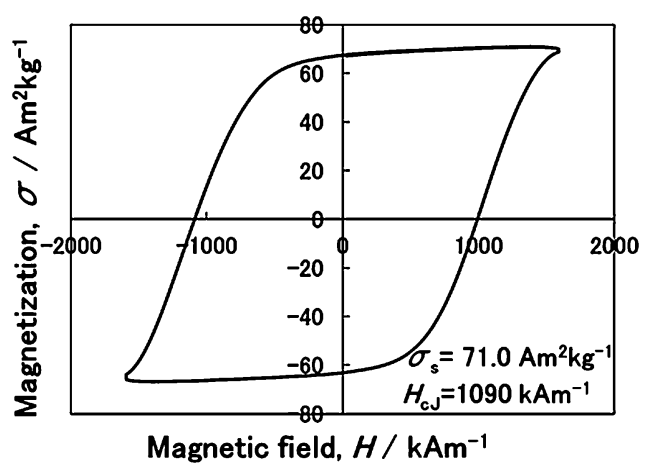

Fig. 15 Hysteresis loop of $\mathrm{MnBi}$ particles annealed at $330^{\circ} \mathrm{C}$ for $5 \mathrm{~h}$ in $\mathrm{Ar}$ and ball-milled for 10 min with a dispersant.

Figure 14 shows the dependence of the magnetic properties of the MnBi particles on the milling time for ball milling carried out at $150 \mathrm{rpm}$ for $30-120 \mathrm{~min}$ with dispersant. Figure 14(a) summarizes $\sigma_{\mathrm{s}}$ and $H_{\mathrm{cJ}}$, and Fig. 14(b) shows the squareness $\left(\sigma_{\mathrm{r}} / \sigma_{\mathrm{s}}\right)$ and energy product $(B H)_{\max }$. From 0 to $10 \mathrm{~min}, \sigma_{\mathrm{s}}$ and $\sigma_{\mathrm{r}} / \sigma_{\mathrm{s}}$ increased sharply and then decreased slightly as the milling time increased. Similarly, $H_{\mathrm{cJ}}$ increased rapidly from 0 to $10 \mathrm{~min}$ and then increased slightly with the milling time. The XRD patterns taken from the samples ball-milled for $30 \mathrm{~min}, 1 \mathrm{~h}$ and $2 \mathrm{~h}$, only XRD peaks from $\mathrm{MnBi}$ were observed and their half widths were similar. This indicates that the samples consisted of the MnBi phase and their crystal structure was not damaged by ball milling. Thus, the sample that was ball-milled for $10 \mathrm{~min}$ exhibited the highest $(B H)_{\max }$ of $105 \mathrm{~kJ} \cdot \mathrm{m}^{-3}$, a $\sigma_{\mathrm{s}}$ of $71.0 \mathrm{Am}^{2} \cdot \mathrm{kg}^{-1}$ and an $H_{\mathrm{cJ}}$ of $1090 \mathrm{kA} \cdot \mathrm{m}^{-1}$. The hysteresis loop for this sample is shown in Fig. 15. The magnetic properties were higher or 
comparable to previously reported values. ${ }^{22-25)}$ The magnetic properties of the $\mathrm{MnBi}$ particles prepared in this study demonstrate that the combination of the hydrogen plasma metal reaction method and ball milling with a dispersant is suitable for preparing fine particles of the MnBi LTP. In addition, further refinement of the preparation conditions to decrease the particle size is required in order to expand the potential applications of the MnBi particles.

\section{Conclusion}

MnBi particles 70-950 $\mathrm{nm}$ in size with an average particle diameter of $269 \mathrm{~nm}$ were prepared by the hydrogen plasma metal reaction method. The magnetic properties of the particles were improved by heat treatment and subsequent ball milling with a dispersant. A relatively high $(B H)_{\max }$ of $105 \mathrm{~kJ} \cdot \mathrm{m}^{-3}$ and $\sigma_{\mathrm{s}}$ of $71.0 \mathrm{Am}^{2} \cdot \mathrm{kg}^{-1}$ were obtained for the sample annealed at $330^{\circ} \mathrm{C}$ for $5 \mathrm{~h}$ in $\mathrm{Ar}$ and then ball-milled for $10 \mathrm{~min}$ with a dispersant. A high $H_{\mathrm{cJ}}$ of $1380 \mathrm{kA} \cdot \mathrm{m}^{-1}$ was also obtained for the sample ball-milled for $2 \mathrm{~h}$.

\section{Acknowledgements}

This research was supported by the Japan Science and Technology Agency (JST), Core Research for Evolutionary Science and Technology (CREST).

\section{REFERENCES}

1) J. Kim, S. E. Chung, S. E. Choi, H. Lee, J. Kim and S. Kwon: Nature Mater. 10 (2011) 747-752.

2) K. L. Tsai, M. Z. Moayyed, R. N. Candler, W. Hu, V. Brand, N. Klejwa, S. X. Wang and R. T. Howe: J. Microelectromech. Syst. 20 (2011) $65-72$.

3) H. Zeng, J. Li, J. P. Liu, Z. L. Wang and S. Sun: Nature 420 (2002)
395-398.

4) D. J. Bakewell: J. Phys. D: Appl. Phys. 44 (2011) 085501.

5) T. Vossmeyer, B. Guse, I. Besnard, R. E. Bauer, K. Müllen and A. Yasuda: Adv. Mater. 14 (2002) 238-242.

6) R. C. Flagan and M. M. Lunden: Mater. Sci. Eng. A 204 (1995) 113124.

7) B. L. Cushing, V. L. Kolesnichenko and C. J. O'Connor: Chem. Rev. 104 (2004) 3893-3946.

8) Y. Sunagawa, K. Yamamoto, H. Takahashi and A. Muramatsu: Catal. Today 132 (2008) 81-87.

9) Y. Wang, Y. Li, C. Rong and J. P. Liu: Nanotechnology 18 (2007) 465701.

10) S. Ohno and M. Uda: J. Jpn. Inst. Metals 48 (1984) 640-646.

11) S. Ohno and M. Uda: J. Jpn. Inst. Metals 53 (1989) 946-952.

12) X. G. Li, A. Chiba and S. Takahashi: J. Magn. Magn. Mater. 170 (1997) 339-345.

13) X. G. Li, T. Murai, A. Chiba and S. Takahashi: J. Appl. Phys. 86 (1999) 1867-1873.

14) X. L. Dong, Z. D. Zhang, S. R. Jin and B. K. Kim: J. Appl. Phys. 86 (1999) 6701-6706.

15) X. G. Li, A. Chiba, S. Takahashi and K. Ohsaki: J. Magn. Magn. Mater. 173 (1997) 101-108.

16) J. G. Lee, P. Li, C. J. Choi and X. L. Dong: Thin Solid Films 519 (2010) 81-85.

17) M. Tanaka and T. Watanabe: Thin Solid Films 516 (2008) 6645-6649.

18) H. J. Williams, R. C. Sherwood and O. L. Boothby: J. Appl. Phys. 28 (1957) $445-447$.

19) X. Guo, X. Chen, Z. Altounian and J. O. S. Olsen: J. Appl. Phys. 73 (1993) 6275-6277.

20) R. R. Heikes: Phys. Rev. 99 (1955) 446-447.

21) T. Chen: J. Appl. Phys. 45 (1974) 2358-2360.

22) D. T. Zhang, S. Cao, M. Yue, W. Q. Liu, J. X. Zhang and Y. Qiang: J. Appl. Phys. 109 (2011) 07A722.

$23)$ J. B. Yang, Y. B. Yang, X. G. Chen, X. B. Ma, J. Z. Han, Y. C. Yang, S. Guo, A. R. Yan, Q. Z. Huang, M. M. Wu and D. F. Chen: Appl. Phys. Lett. 99 (2011) 082505.

24) K. Y. Ko, S. J. Choi, S. K. Yoon and Y. S. Kwon: J. Magn. Magn. Mater. 310 (2007) e887-e889.

25) J. B. Yang, W. B. Yelon, W. J. James, Q. Cai, S. Roy and N. Ali: J. Appl. Phys. 91 (2002) 7866-7868 